\title{
Total syntheses of the archazolids: an emerging class of novel anticancer drugs
}

\author{
Stephan Scheeff and Dirk Menche*
}

\author{
Review \\ Address: \\ Kekulé-Institut für Organische Chemie und Biochemie, Universität \\ Bonn, Gerhard-Domagk-Strasse 1, 53121 Bonn, Germany \\ Email: \\ Dirk Menche ${ }^{*}$ - dirk.menche@uni-bonn.de \\ * Corresponding author \\ Keywords: \\ anticancer agent; medicinal chemistry polyketides; synthetic \\ methodology; total synthesis
}

\author{
Beilstein J. Org. Chem. 2017, 13, 1085-1098. \\ doi:10.3762/bjoc. 13.108 \\ Received: 07 March 2017 \\ Accepted: 09 May 2017 \\ Published: 07 June 2017 \\ This article is part of the Thematic Series "Lipids: fatty acids and \\ derivatives, polyketides and isoprenoids". \\ Guest Editor: J. S. Dickschat
}

(C) 2017 Scheeff and Menche; licensee Beilstein-Institut.

License and terms: see end of document.

\begin{abstract}
V-ATPase has recently emerged as a promising novel anticancer target based on extensive in vitro and in vivo studies with the archazolids, complex polyketide macrolides which present the most potent V-ATPase inhibitors known to date, rendering these macrolides important lead structures for the development of novel anticancer agents. The limited natural supply of these metabolites from their myxobacterial source renders total synthesis of vital importance for the further preclinical development. This review describes in detail the various tactics and strategies employed so far in archazolid syntheses that culminated in three total syntheses and discusses the future synthetic challenges that have to be addressed.
\end{abstract}

\section{Introduction}

The complex structures of polyketides continues to be a great challenge for synthetic chemists and has also been a key driver for the development of new methodologies [1-9]. In many cases, total synthesis is of critical importance to enhance the supply of these often scarce metabolites and even complex polyketides have been prepared on an industrial scale $[10,11]$. These natural products are also valuable molecular probes for the discovery and evaluation of novel biological targets and pathways $[12,13]$. Vacuolar-type ATPases (V-ATPases) are heteromultimeric proton translocating proteins that are local- ized in a multitude of eukaryotic membranes [14-16] that have been known as key mediators in a variety of biochemical pathways. They are responsible for a variety of important cellular functions, including $\mathrm{pH}$-control [17,18], membrane trafficking, protein degradation, release of neurotransmitters [18], urinary acidification [19], bone resorption [20], sperm maturation [21], cholesterol biosynthesis [22] and cytokine secretion [23]. In recent years, a key role of these multimeric enzymes also in cancer development and progression was discovered and has been increasingly unraveled. The archazolids, polyketide 
macrolides from the myxobacterium Archangium gephyra, have played a key role in these studies. They present the most potent V-ATPase inhibitors known to date with activities in the low nanomolar range [24,25], by binding to the functional transmembrane subunit c $[26,27]$, and display highly potent growthinhibitory activities against a range of cancer cell lines, both in vitro and in vivo [23,28-34]. In detail, archazolid inhibition of V-ATPase abrogates tumor metastasis via repression of endocytic activation [28], leads to impaired cathepsin B activation in vivo [30], modulates anoikis resistance and metastasis of cancer cells [31], overcomes trastuzumab resistance of breast cancers [32], blocks iron metabolism and thereby mediates therapeutic effects in breast cancers [33], and plays a role in tumor sensitizing in the context of the MDM2 antagonist nutlin-3a [34]. Based on these studies V-ATPases have been increasingly emerging as an extremely promising novel anticancer target [26,27,35-37] and the archazolids have become important lead structures for the development of novel anticancer agents.

As shown in Scheme 1 for the most prominent representatives archazolid A (1) and B (2) [38-40], their unique architectures are characterized by a 24 -membered macrolactone ring with seven alkenes, including a characteristic $(Z, Z, E)$-triene, a thiazole side chain and a characteristic sequence of eight methyl and hydroxy-bearing stereocenters.

Synthetic chemistry is of key importance to enhance the supply of these scarce polyketides to fully evaluate the biological potential and develop them as potential drug candidates. The important biological properties in combination with their limited natural supply as well as their intriguing molecular architectures and initially unknown stereochemistry, have rendered the archazolids as highly attractive synthetic targets and so far, three total syntheses have been reported by the groups of Menche and Trauner [41-43]. Furthermore several fragment syntheses as well as methodological studies to access key structural elements have been published in the last years [44-54]. Recently, the focus has been increasingly shifted towards analog development and SAR studies [49,55-58] and the group of O'Neil has been targeting dihydroarchazolid B (3) as a potentially equipotent structurally simplified derivative $[45,46,48]$. This review covers the various tactics and strategies, employed by the Menche, Trauner and O'Neil group in archazolid syntheses and discusses the challenges for the development of a scalable route.

\section{Review}

The first total synthesis of archazolids A and B were independently developed by the Menche group and the group of Trauner in 2007 by completely independent routes. In 2009, a second total synthesis of archazolid B has been described again by the Menche group following a sequence that was related to their archazolid A synthesis.

\section{Menche's retrosynthetic analysis and strategy}

As a prelude to initiating a synthetic campaign directed towards the archazolids the Menche group first elucidated the full stereochemistry and three dimensional conformation of the archazolids by NMR methods, molecular modelling and chemical derivatizations $[59,60]$. During these studies, they became aware that $\mathrm{C} 2-\mathrm{C} 5$ diene of acyclic analogs would be very labile towards isomerization. However, such processes would be suppressed in the macrolide natural products, presumably due to conformational factors. In contrast, the $Z, Z, E$-triene system at northern part of the target molecule (i.e., C9 to C14) was stable,

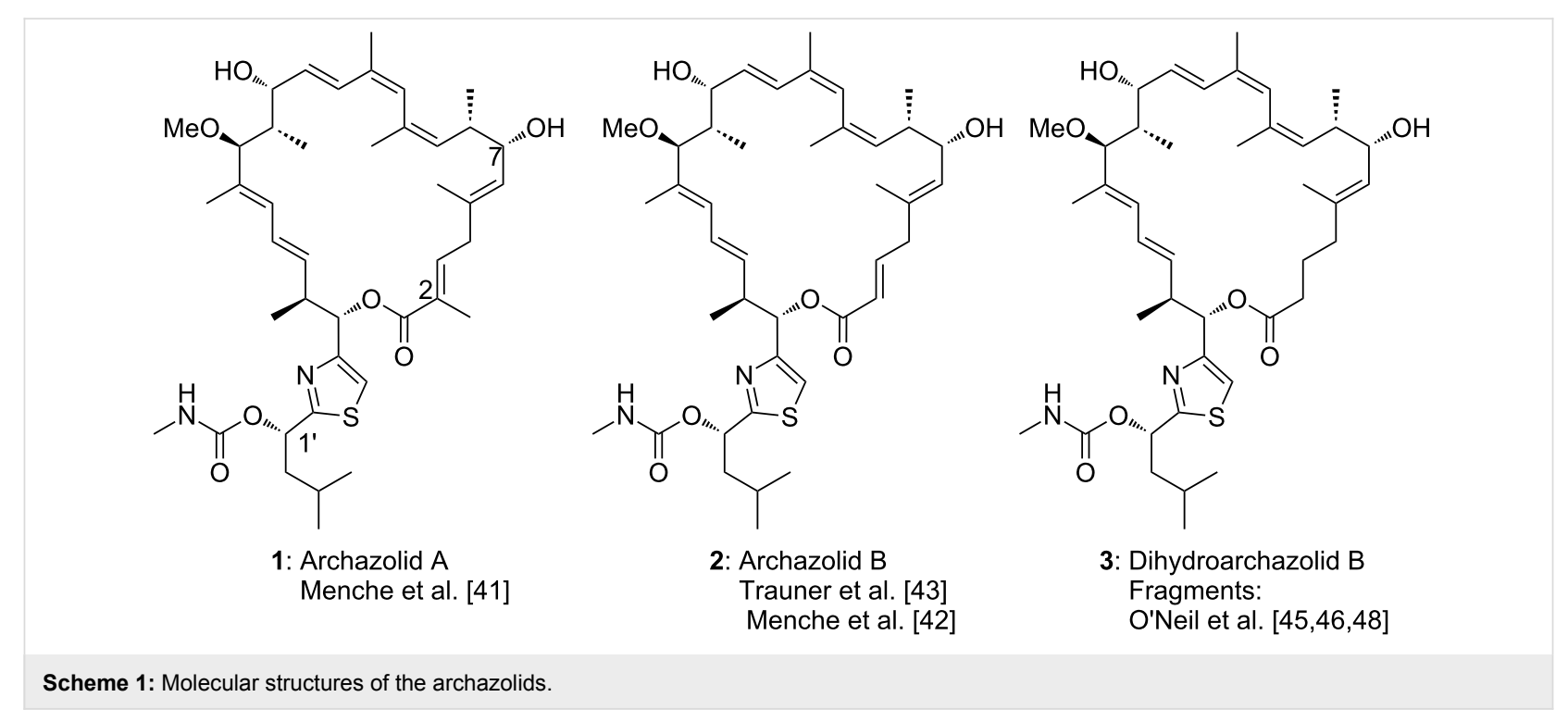


also in an acyclic state, presumably due to distortion of the conjugated system due to constraints exerted by the methyl groups at $\mathrm{C} 10$ and $\mathrm{C} 12$. Based on this analysis, their synthetic plan was to first build the triene, while the $\mathrm{C} 2-\mathrm{C} 5$ fragment should be constructed directly before or during ring closure as shown in Scheme 2. Consequently, they first planned to connect the north-eastern fragment $\mathbf{5}$ with the propionate unit $\mathbf{4}$ by a suitable olefination strategy. Subsequently, for connecting the resulting fragment to the thiazole subunit $\mathbf{6}$ a Heck reaction was envisioned as part of studies advancing this type of Palladiumcatalyzed coupling strategies in complex target synthesis [6166]. Finally, a HWE-macrocyclization was planned which would likewise set the labile $\mathrm{C} 2-\mathrm{C} 5$ diene and thus concomitantly stabilize this functionality by macrocyclic constraints.

\section{Menche's total synthesis of archazolid A Synthesis of the north-eastern fragment}

As shown in Scheme 3, the construction of the north-eastern fragment 5 relied on a boron-mediated anti-aldol reaction [67] of lactate-derived ethyl ketone 13 with aldehyde 12, which in turn was available from aldehyde 9 by HWE olefination. This Paterson aldol reaction and related aldol reactions, which have been amply used by the Menche group [68-70], proceeded with excellent yield and selectivity. The resulting $\beta$-hydoxyketone 14

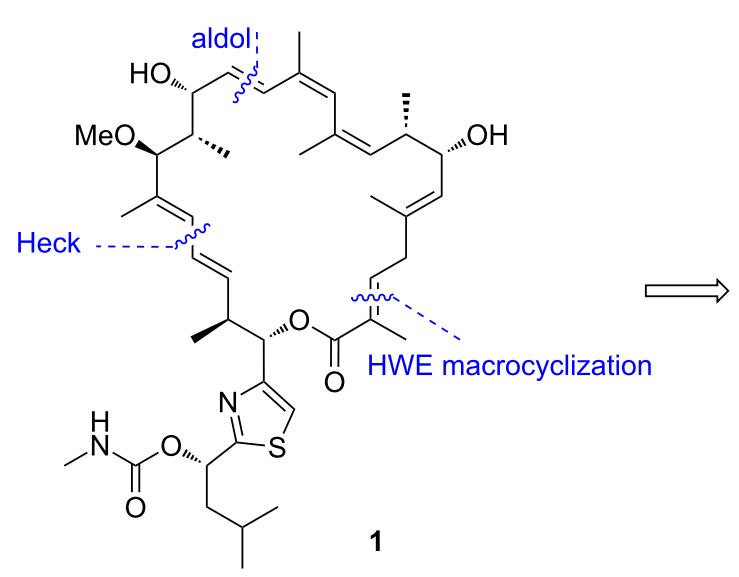<smiles>COC(C(C)=CI)[C@@H](C)C(C)=O</smiles><smiles>C=CC(C)[C@H](O)c1csc([C@@H](CC(C)C)OC(=O)NC)n1</smiles><smiles>C/C(C=O)=C/C(C)=C/[C@H](C)[C@@H](/C=C(\C)CCOC(C)(C)C)O[Sb]</smiles>

5<smiles>[3H]C(C(=O)O)P(=O)(OC)OCC</smiles>

Scheme 2: Retrosynthetic analysis of archazolid A by the Menche group.

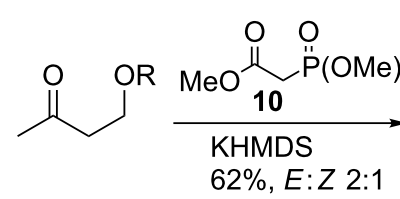<smiles>[X]C(=O)C=C(C)CCOC(C)=O</smiles>

OPMB<smiles>CC(=O)OC(=O)CCCCCC(=O)C(C)C</smiles>

8: $\mathrm{R}=\mathrm{H} \longrightarrow \mathrm{PMBTCA}$
9: $\mathrm{R}=\mathrm{PMB}$
$77 \%$

11: $\mathrm{X}=\mathrm{OMe} \rightarrow$ 1. DIBALH

$85-99 \%$

ds $>20: 1$

2. $\mathrm{MnO}_{2}$

96\% (2 steps)

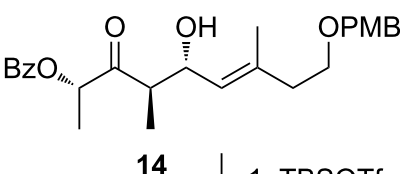

14

2. $\mathrm{LiBH}_{4}$

3. $\mathrm{NaIO}_{4}$

$85 \%$

$\downarrow$ (3 steps)

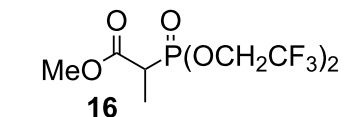

KHMDS, 18-crown-6

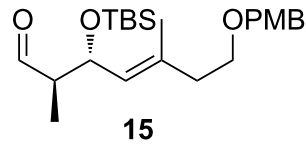

17

ds $>20: 1$

15

1. 16, KHMDS, 18-crown-6

2. DIBALH

3. DMP<smiles>[R16]OCCC(C=[18O])=C[C@@H]([SeH])C(C)C=C(C)C=O</smiles>

$78 \%$
(3 steps)

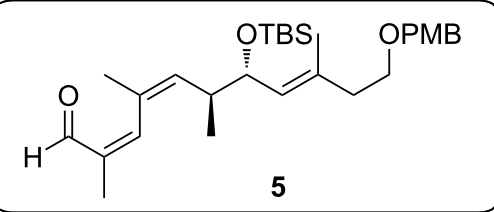

Scheme 3: Synthesis of north-eastern fragment 5 through a Paterson anti-aldol addition and multiple Still-Gennari olefinations. 
was then protected as TBS ether and converted to aldehyde $\mathbf{1 5}$ by reductive removal of the benzoate group and periodate cleavage. Notably, depending on the choice of protection group, deprotection and further oxidation with $\mathrm{NaIO}_{4}$ may be observed, a procedure that was further studied by the group [71]. The two vicinal $Z$-alkenes were then installed by two consecutive Still-Gennari olefinations [72] with aldehydes $\mathbf{1 5}$ and $\mathbf{1 8}$ In both cases coupling with the Still-Gennari reagent $\mathbf{1 6}$ gave $\mathbf{1 7}$ and after reduction the final building block 5 was formed in high yields and selectivity. While the overall sequence towards 5 consequently required twice a two-step adaption of the oxidation state which renders this route quite lengthy, the authors argue that the robustness, facile conduction and scalability of each step was very high and made them decide to stick to this sequence as compared to likewise tested alternatives.

\section{Synthesis of the north-western fragment}

For the construction of the north-western fragment 4 the Menche group opted to first install the terminal $E$-configured vinyl iodide. While appearing to be a simple problem, quite some efforts had to be invested, before acid $\mathbf{2 1}$ could be efficiently obtained as shown in Scheme 4. Finally, after optimization of a reported procedure [73] the successful route employed a one-pot process involving a sodium hydride-mediated coupling of methyl malonate 19 with iodoform (20) followed by a stereoselective elimination and decarboxylation in situ. The corresponding aldehyde $\mathbf{2 2}$ was then homologated by an Abiko-Masamune anti-aldol addition [74] with ephedrinederived ester 23, which proceeded with excellent yield and stereoselectivity. However, the subsequent removal of the sterically hindered chiral auxiliary proved demanding. The Menche group realized that a transformation to a Weinreb amide may be realized in an effective manner by an in situ activation of $\mathbf{2 4}$ with iPrMgCl [75], followed by a methylation of the free hydroxy group and introduction of the methyl ketone. This procedure proved superior to an original sequence involving a reductive cleavage of the auxiliary.

\section{Synthesis of the southern fragment}

The same southern fragment $\mathbf{6}$ was independently chosen by the Menche group in their total synthesis of archazolid A and by the Trauner group in their total synthesis of archazolid B. Both groups also pursued identical routes to this subunit. As shown in Scheme 5, this sequence started from L-leucine (26) which was first converted with nitrous acid to the hydroxy acid $\mathbf{2 7}$, which proceeds with retention of the configuration due to intermediate lactone formation after generation of the diazoniumintermediate [76]. After conversion to amide $\mathbf{2 8}$ and thioamide 29 the thiazole $\mathbf{3 1}$ was obtained by condensation with bromoester 30. The carbamate was then introduced by activation of the deprotected hydroxy group with carbonyldiimidazole and treatment with methylamine, before the ester was selectively reduced to the aldehyde 32 with DIBALH. Finally, a Brown crotylation [77] set the two vicinal stereogenic centers of 6 with high stereoselectivity. In total this route enabled an efficient and reliable access to this key fragment. However, one drawback of this sequence was a tendency of epimerisation at $\mathrm{C} 1$ ' during thiazole formation on large scale, requiring an oxidation-reduction sequence $(90 \%)$ in this case.

\section{Completion of the total synthesis}

After evaluation of several strategies, the assembly of the two northern fragments $\mathbf{4}$ and $\mathbf{5}$ could be realized by an aldol condensation, involving a boron-mediated aldol coupling, acetate protection of the newly generated hydroxy group and DBUmediated elimination. This three-step sequence proceeded as shown in Scheme 6 with excellent yields (94\%) giving the triene $\mathbf{3 3}$ as a single diastereomer, which demonstrates the

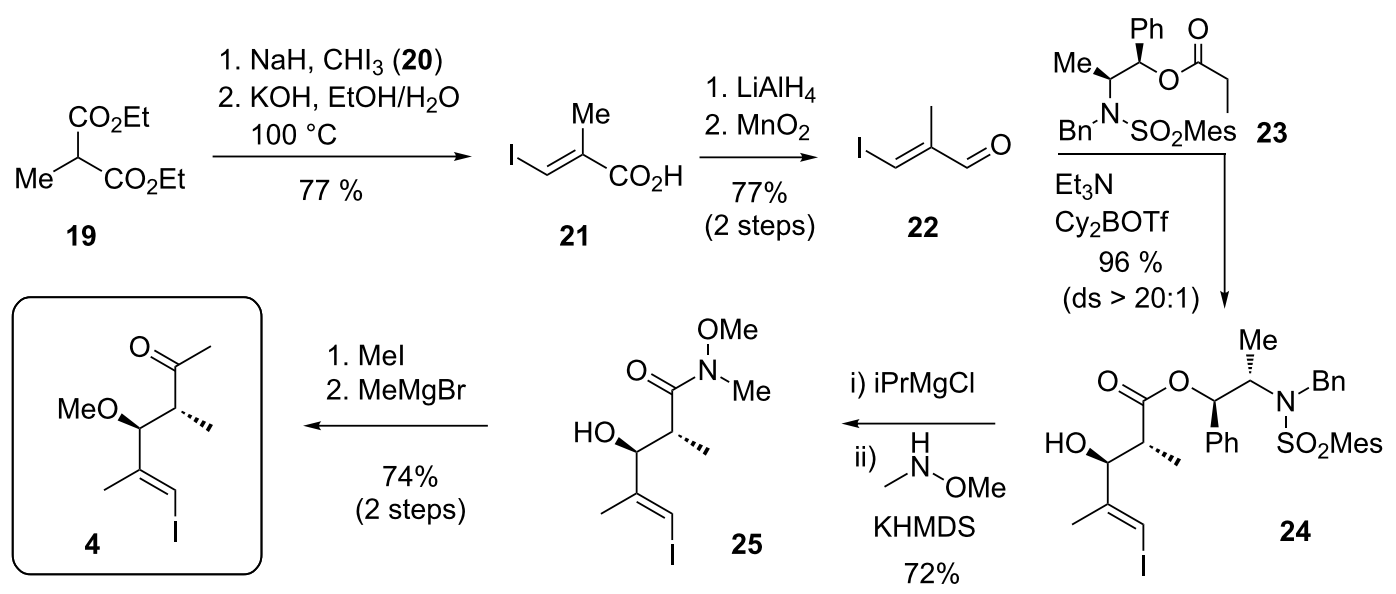


<smiles>CC(C)C[C@H](N)C(=O)O</smiles>

26

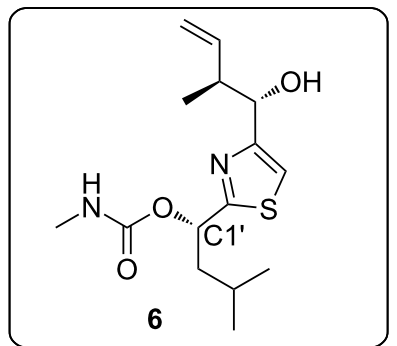<smiles>CC(C)C[C@H](O)C(=O)O</smiles>

27

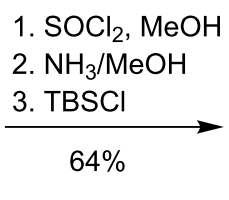<smiles>CC(C)CC(OS(C)(=O)=O)C(N)=O</smiles>

28<smiles>CC(C)CC(O[Ga])C(=S)NC(C)(C)C</smiles>

29

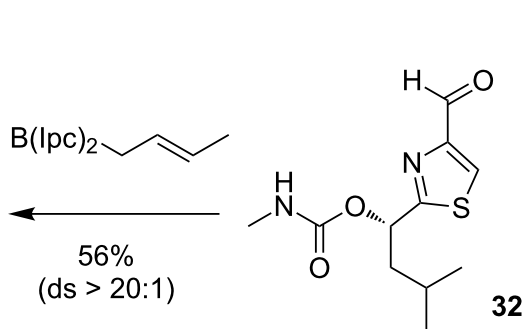

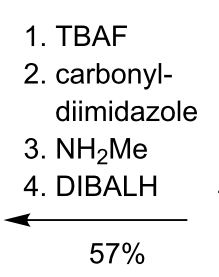

$79 \% \underbrace{\mathrm{Br}}_{30} \stackrel{\mathrm{O}}{\mathrm{CO}_{2} \mathrm{Et}}$

Scheme 5: Thiazol construction and synthesis of the southern fragment 6 .

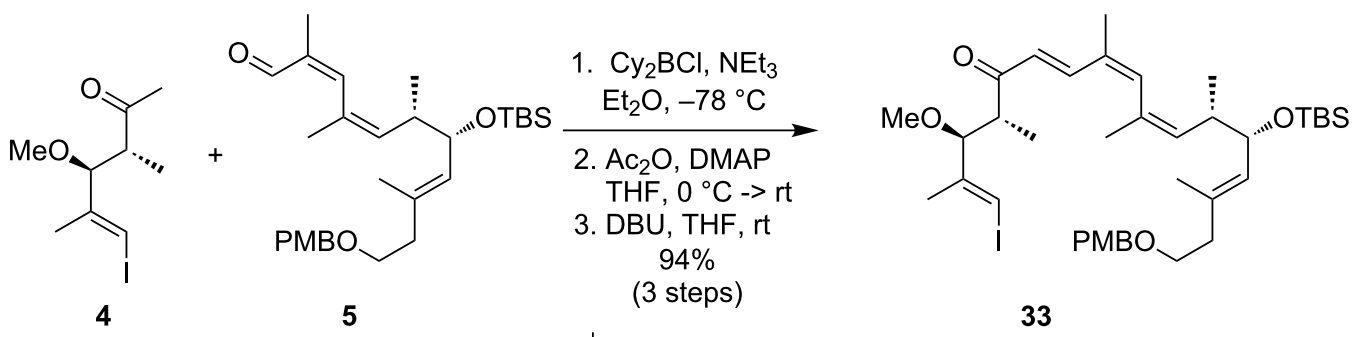<smiles></smiles>

Scheme 6: Completion of the total synthesis of archazolid A. 
usefulness of aldol condensations in complex target synthesis, also on highly elaborate substrates. Considerable efforts were invested before the challenging Heck coupling with the thiazole fragment 6 could be effected with useful selectivities. Besides the desired $E, E$-diene $\mathbf{3 4}$ formation of other double bond isomers both in the southern and northern part of the molecule could not be suppressed and required a tedious HPLC separation at this stage. After attachment of the phosphonate 7 , aldehyde 35 was obtained by removal of the PMB group and oxidation of the primary alcohol. The moderate yields of this sequence are mainly due to side reactions in the deprotection step. The Menche group then had considerable difficulties in closing the macrocyclic ring using an HWE reaction. Finally, the macrocylization could be realised by using $\mathrm{NaH}$ as a strong non-nucleophilic base. It proved essential to perform this reaction in the presence of molecular sieves to remove any traces of water which were shown to lead to unfavourable isomerization pathways. Finally, an oxazaborolidine-assisted borane reduction [78] set the stereogenic center at C15 and global deprotection gave synthetic archazolid A, which proved to be fully identical with a natural sample, thus unambiguously confirming the stereochemistry of this macrolide [59].

\section{Menche's total synthesis of archazolid B}

One the methodological incentives of the synthetic campaign of the Menche group directed towards the archazolids were the further development and application of the Heck reaction in complex target synthesis. Accordingly, they applied a Heck macrocyclization strategy for the total synthesis of archazolid B. As shown in Scheme 7, this strategy could be successfully implemented and the macrocyclic core of the target compound was obtained in useful yields by coupling of 38, which in turn was accessible by an intermolecular HWE reaction of $\mathbf{3 6}$ with 37 using the procedure evaluated above. Final stereoselective
CBS reduction and global deprotection liberated archazolid B in $41 \%$ yield over 3 steps [42]. This accomplishment presented the second total synthesis of this macrolide while the first total synthesis was enabled by the group of Trauner and will be discussed below.

\section{Trauner's retrosynthetic analysis and strategy}

Shortly after the total synthesis of archazolid A (1) by Menche et al. [41] the total synthesis of archazolid B 2 was reported by Trauner and co-workers [43]. As shown in Scheme 8, they could successfully couple the three main fragments 39, 40 and 6 by first a Stille reaction, followed by a Kita esterification. Notably, this esterification was critical to avoid unfavorable isomerizations. For closing of the macrolide core they planned a challenging Hoye relay ring closing metathesis (RRCM) which would lead directly after deprotection to archazolid B (2).

\section{Trauner's total synthesis of archazolid B Synthesis of the north-eastern fragment}

The synthesis of fragment $\mathbf{4 0}$ started with the literature-known protocol for generation of ynone $\mathbf{4 2}$ derived from $(S)$-Roche ester 41 [79] as shown in Scheme 9. After reduction the alcohol was protected with TIPS and the TBS ether was cleaved by acetic acid to get to the primary alcohol $\mathbf{4 3}$. The reduction with $(S)$-alpine borane was highly diastereoselective ( $d r>20: 1)$. Following this sequence over 6 steps the two stereogenic centers at $\mathrm{C} 7$ and $\mathrm{C} 8$ were successfully built up. The primary alcohol of fragment $\mathbf{4 3}$ was then oxidized by the Dess-Martin reagent (DMP) and then treated with $\mathrm{CBr}_{4}$ and $\mathrm{PPh}_{3}$ to generate the dibromoalkene $\mathbf{4 4}$ in high yield of $75 \%$ over 2 steps. The group now installed the vinyliodide for the Stille coupling by treating the alkene with lithium dimethylcuprate. In comparison with the likewise attempted Stork-Zhao olefination this protocol by Tanino and Miyashita was superior in yield and<smiles>C=CC(C)[C@H](OC(=O)C[P+](=O)OCC)c1csc([C@H](CC(C)C)OC(=O)NC)n1</smiles> 


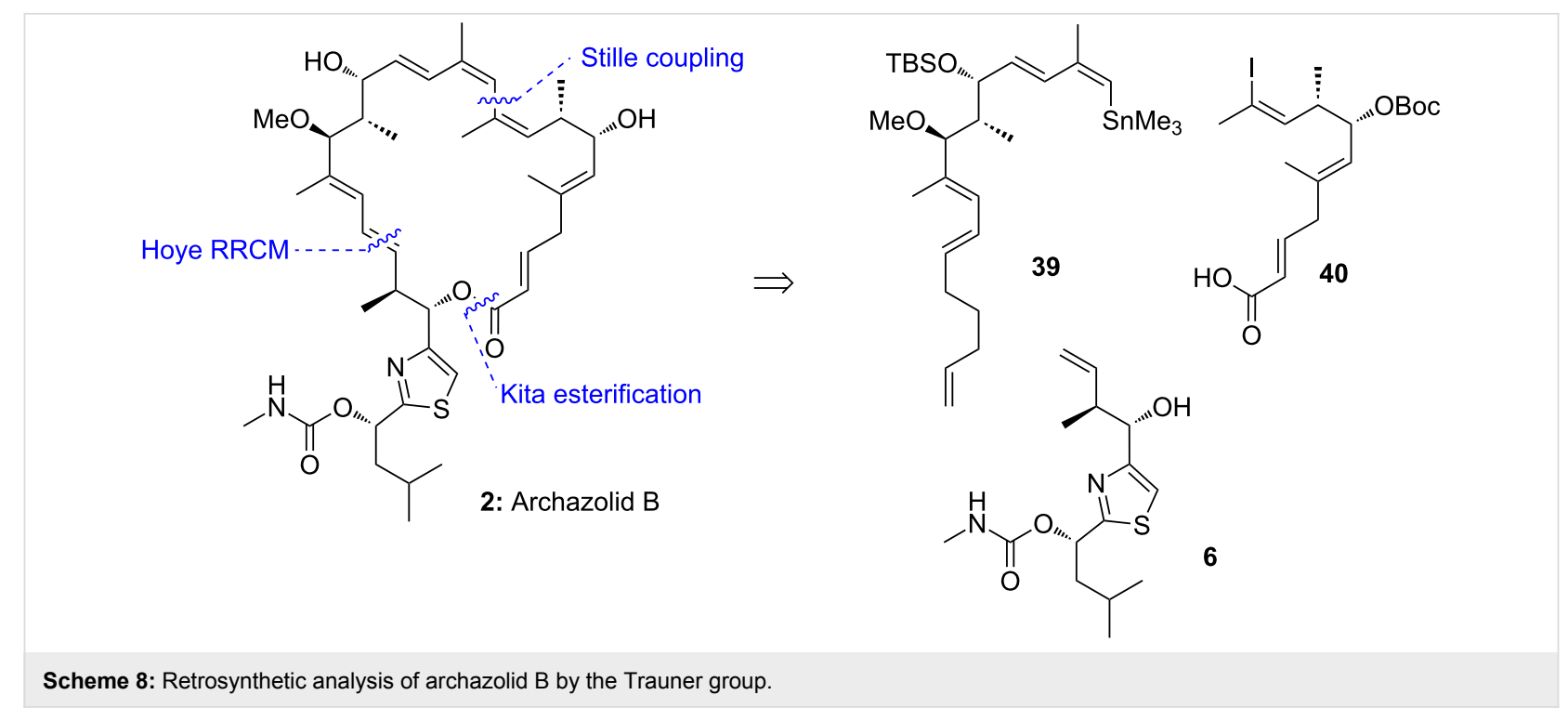

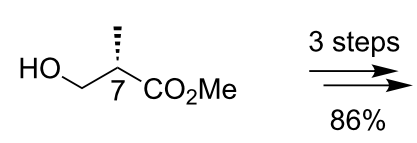

41

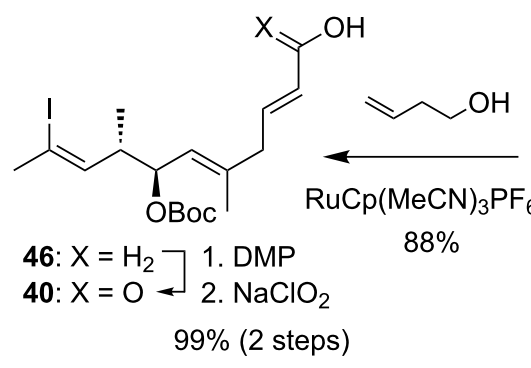

1. (S)-Alpine-borane

\section{TIPSCl \\ 3. HOAC \\ $80 \%$ (3 steps)}

$(d r>20: 1)$

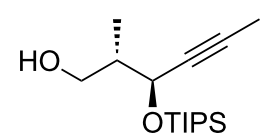

43

Scheme 9: Synthesis of acid $\mathbf{4 0}$ from Roche ester $\mathbf{4 1}$ involving a highly efficient Trost-Alder ene reaction.

stereoselectivity [80]. To complete the fragment synthesis the [Ru]-catalyzed Trost-Alder-ene reaction [81] generated the desired primary alcohol which was oxidized in 2 steps with DMP and $\mathrm{NaClO}_{2} / \mathrm{NaH}_{2} \mathrm{PO}_{4}$ to the free acid 40. The high regioselectivity of the Alder-Ene reaction is remarkable and was argued to be derived by a coordinating effect of the carbonate. Also, the overall high yield for synthesis of this elaborate vinyl iodide is impressive.

\section{Synthesis of the north-western fragment}

As shown in Scheme 10, the synthesis of stannane 39 started with aldehyde 48 which was derived from propargyl alcohol in five steps [82]. After DMP oxidation the generated aldehyde 48 underwent a syn-selective Evans aldol addition with oxazolidinone 47 to obtain the alcohol 49 in $76 \%$ over 2 steps [83]
Before TBS protection the Weinreb amide was generated and then conversed into the phosphonate $\mathbf{5 0}$ as a precursor for a Horner-Wadsworth-Emmons reaction. The olefination led to unsaturated ketone $\mathbf{5 2}$ in $\mathbf{7 9 \%}$ yield. For the final fragment synthesis the ketone was reduced with sodium borohydride to generate all three required stereogenic centers for this fragment with excellent diasteroselectivity. Final methylation of the free alcohol was followed by conversion of the vinyl iodide into the desired stannane to get fragment $\mathbf{3 9}$ which was used directly for coupling.

\section{Completion of the total synthesis}

Final assembly of the fragments as shown in Scheme 11 began with an unusual $[\mathrm{Ru}]$-catalyzed Kita esterification due to the instability of fragment $\mathbf{4 0}$ towards basic esterification ap- 

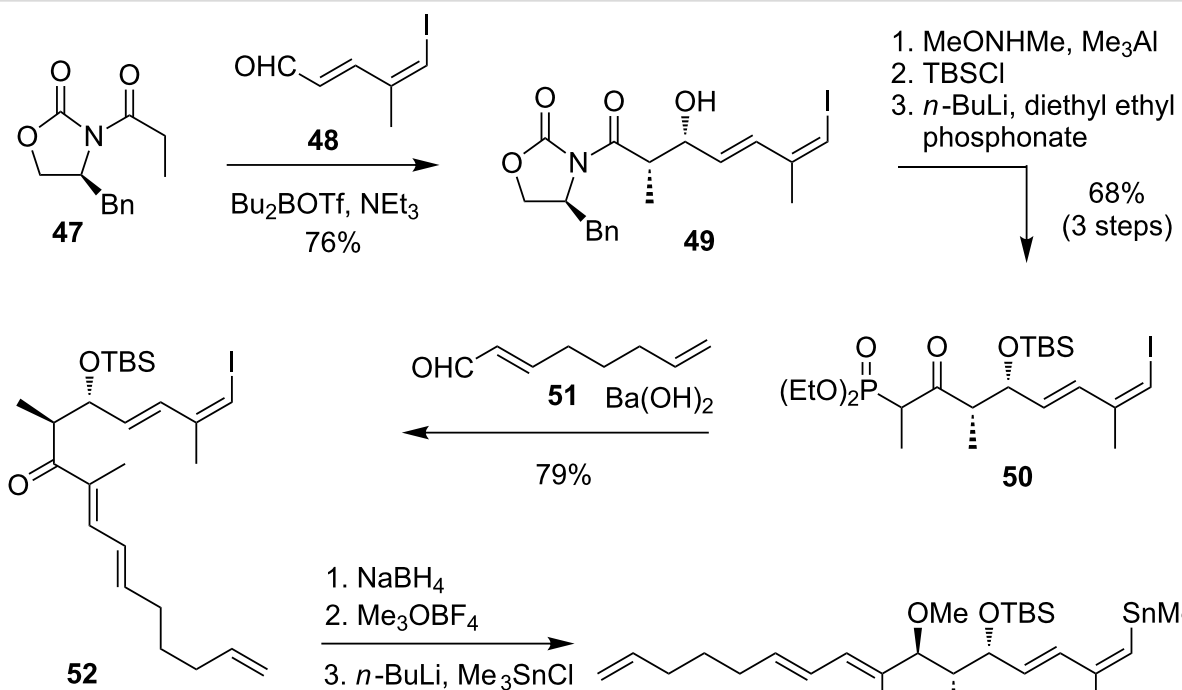

1. $\mathrm{NaBH}_{4}$

2. $\mathrm{Me}_{3} \mathrm{OBF}_{4}$

$\sim 82 \%$ (3 steps)

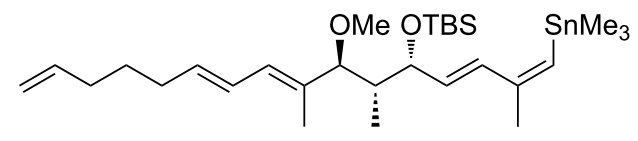

39

Scheme 10: Synthesis of precursor 39 for the projected relay RCM reaction.<smiles>C=C[C@H](C)[C@H](O)c1csc([C@@H](CC(C)C)OC(=O)NC)n1</smiles><smiles>[R5]CS/C=C(C)/C=C/[C@H](O[B-])[C@H](C)[C@@H](OC)/C(C)=C/C=C/CCCC=C</smiles>

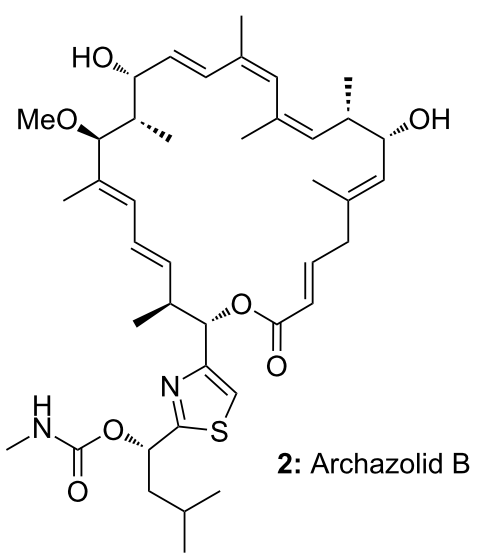

1. Grubbs II $(27 \%)$ 2. $\mathrm{HCOOH}(84 \%)$

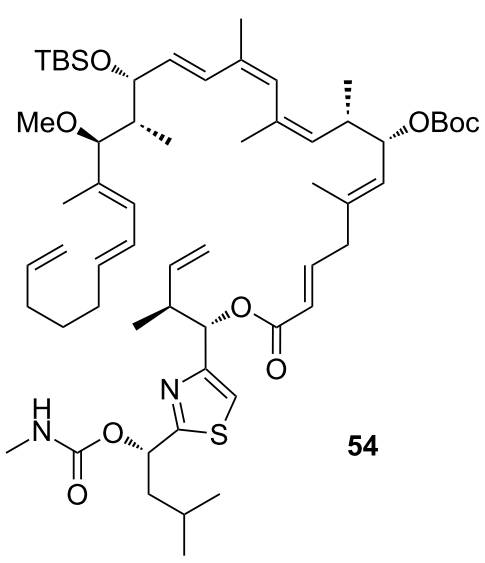


proaches [84]. The following Stille coupling with stannane 39 was then accomplished by CuTC co-catalysis to get the final fragment 54 in 32\% yield [85,86]. The envisioned Hoye relay RCM was catalyzed by Grubbs' second generation catalyst to close the macrocycle in $27 \%$ yield. The final acid-mediated deprotection liberated finally archazolid B (2). Notably, no cyclization was observed in an analogous RCM reaction with a substrate without the relay tether, which underscores the usefulness of this relay tactic.

It is important to mention, that the three main fragments were coupled in only four steps, showing the highly modular approach from Trauner and co-workers. With this strategy it was possible to synthesize archazolid B (2) in only 19 steps from (S)-Roche ester 41 (longest linear sequence).

\section{O'Neil's retrosynthetic analysis and strategy}

As discussed above one of the main difficulties of any archazolid synthesis involves the labile $\mathrm{C} 1$ to $\mathrm{C} 5$-dienoate system, which is prone to isomerization. However, the similar biological potency of archazolids A and B as well as the archazolid B isomer archazolid F, which bears a 3,4- instead of the 2,3alkene, suggest that the $\mathrm{C} 2$-olefin may not be essential for the biological potency. Accordingly, the group of O'Neil and co-workers has been targeted dihydroarchazolid B (3). They assumed a similar biological potency of the derivative with simultaneous simplification of the synthesis. While so far, they have not been able to finish this synthesis, they have reported several very instructive and efficient fragment syntheses, including the three main fragments 55, 56 and $\mathbf{5 7}$ as shown in Scheme 12 [45,46,48]. The challenging ring-closing metathesis between $\mathrm{C} 13$ and $\mathrm{C} 14$ could not be established mainly due a competing backbiting process of the corresponding western fragment [46].

\section{O'Neil's syntheses of advanced dihydroarchazolid $B$ fragments \\ Synthesis of the macrocyclic skeleton}

Based on this unsuccessful approach $\mathrm{O}^{\prime} \mathrm{Neil}$ and co-workers published a new synthetic route towards 2,3-dihydroarchazolid B (3) [48]. As shown in Scheme 13 they were able to synthesize the macrocyclic skeleton $\mathbf{6 8}$ by a Stille coupling between stannane 56 and iodide 55 as the key step. Notably, they had to switch the halide/organometallic functionality of each building block after an unsuccessful coupling between the stannane synthesized by reduction and methylation of ketone $\mathbf{6 7}$ and the iodine derived from fragment $\mathbf{6 2}$. They assume that the steric hindrance of the methyl group in $\mathrm{C} 10$ position possibly lowers the reactivity of the iodine in the oxidative addition step in the catalytic cycle.

For the synthesis of stannane $\mathbf{5 6}$ the authors could benefit from the previous fragment synthesis. In 2010 they first published an approach to an eastern building block through an allylationelimination sequence to form the triene system C9 to C14 [44]. In a second generation fragment synthesis building block $\mathbf{6 2}$ was firstly synthesized in 2014 [46]. Starting with the TBS-protected alkyne 58 [87] a zirconium-mediated carboalumination reaction [88] and subsequent coupling with aldehyde $\mathbf{5 9}$ gave alcohol 60. In this $\Delta^{5,6}$-trans-selective reaction the desired antidiastereomer could be isolated in $85 \%$ with a dr of $6: 1$, which presumably arises from a chelation-controlled stereoselectivity [89]. The aldehyde $\mathbf{5 9}$ itself can be prepared in two steps from the corresponding Roche ester [90]. After protection of the free

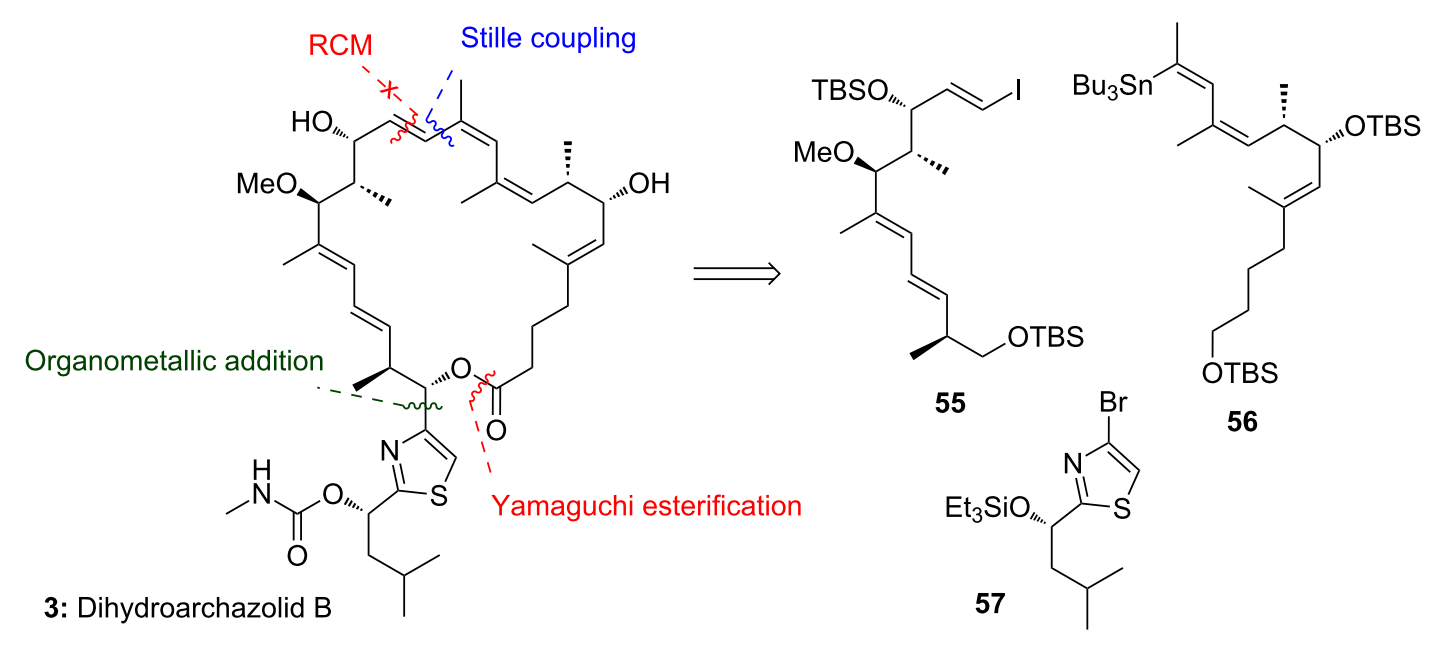



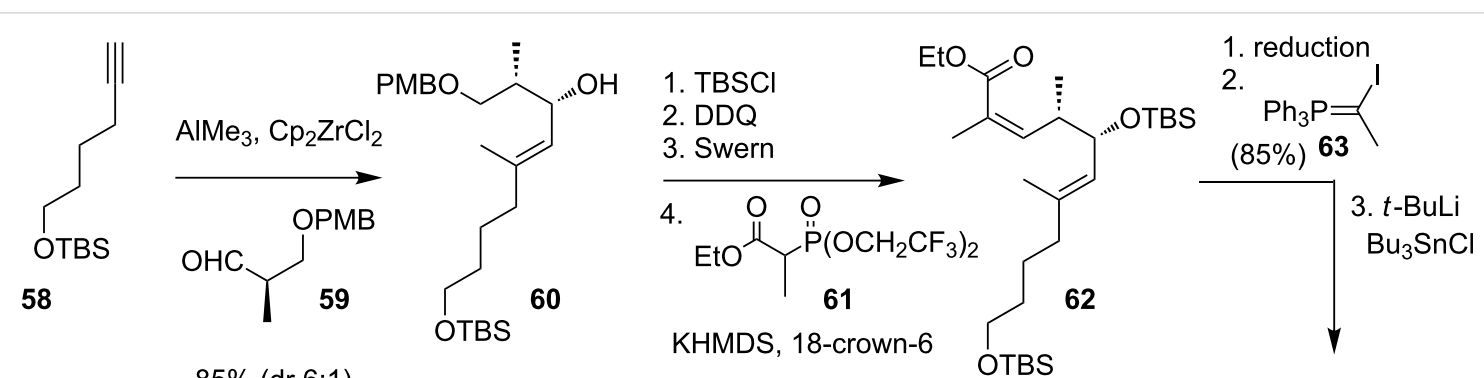

$85 \%(\mathrm{dr} 6: 1)$
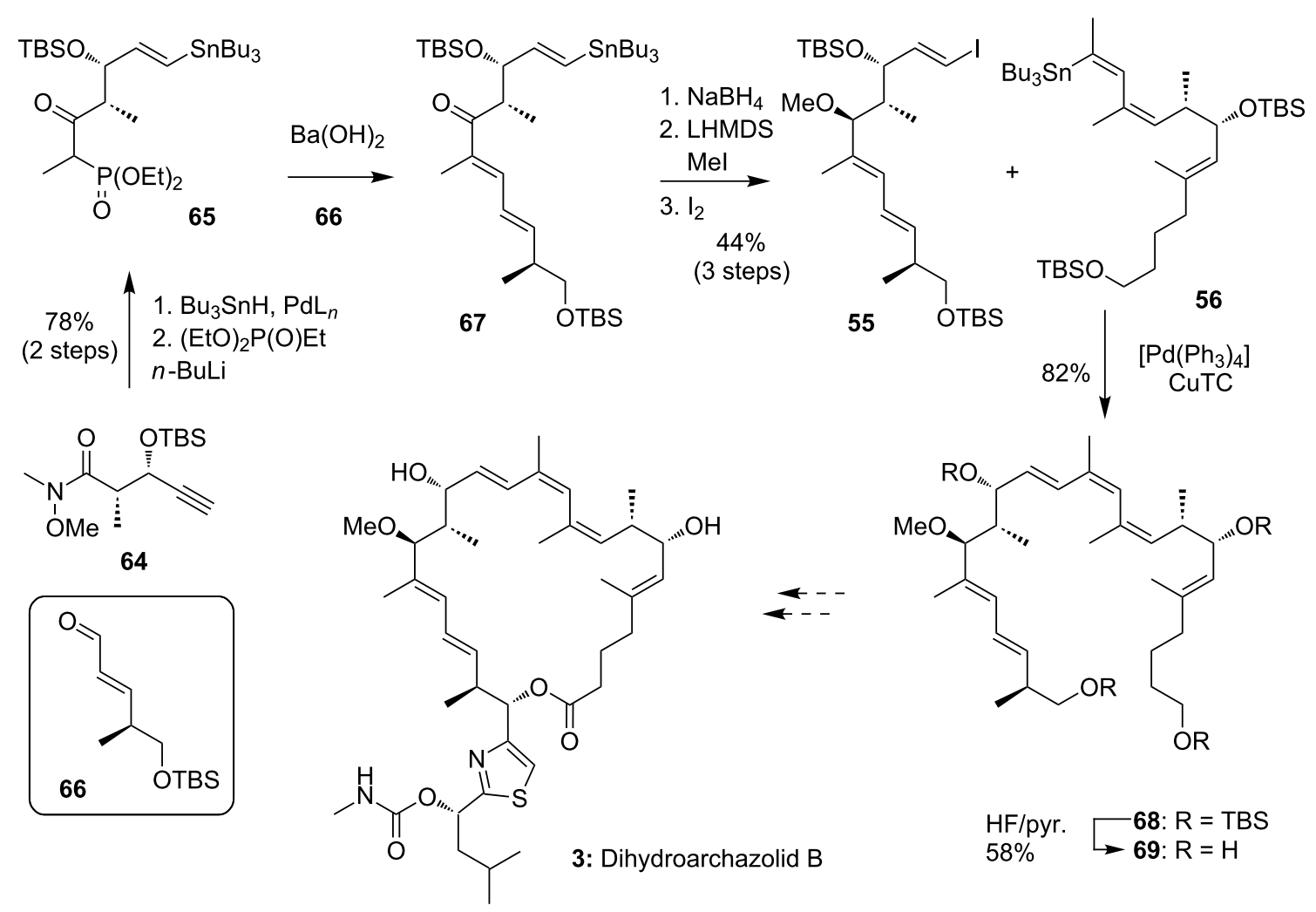

Scheme 13: Fragment synthesis of 69 towards the total synthesis of 3 .

alcohol and deprotection of the primary PMB-protected alcohol with DDQ, the resulting alcohol was oxidized to the corresponding aldehyde. The crude aldehyde was then directly transformed into the $(Z)-\alpha, \beta$-unsaturated ester $\mathbf{6 2}$ as a single stereoisomer by a Still-Gennari [72] olefination with phosphonate $\mathbf{6 1}$ in an excellent yield of $93 \%$ over 4 steps. After reduction of ester $\mathbf{6 2}$ to the corresponding aldehyde (by a method that was not specified by the authors) phosphorane $\mathbf{6 3}$ was used to generate the respective $Z$-vinyl iodide in $85 \%$ yield as an $8: 1$ $(Z, Z):(Z, E)$ mixture [91] which was later switched to the stannane 56 by lithium-halogen exchange and further treatment with $\mathrm{Bu}_{3} \mathrm{SnCl}[92]$ in $90 \%$ yield.

The synthesis of the coupling partner $\mathbf{5 5}$ started with known Weinreb amide 64 which underwent a $s y n$-selective palladiumcatalyzed hydrostannylation and was then transformed to phos- phonate $\mathbf{6 5}$ in good yield. For coupling with known aldehyde 66 [93] the O'Neil group chose $\mathrm{Ba}(\mathrm{OH})_{2}$ as base for the HWE-type reaction [94] to generate the $\alpha, \beta$-unsaturated ketone 67 in $75 \%$ yield as a 10:1 mixture of isomers. Similar to the earlier discussed synthesis of Trauner and co-workers [43] reduction with sodium borohydride delivered the desired alcohol in a 10:1 diastereoselectivity. The alcohol was methylated by a protocol involving methyl iodide and LiHMDS, that had been previously used by the group [45]. The stannane was finally converted to the iodide $\mathbf{5 5}$ by iododestannylation [95] to complete the fragment synthesis in $44 \%$ yield over 3 steps.

For the final step the authors decided to follow a Stille coupling protocol established by Fürstner et al. [96] with CuTC as co-catalyst and $\left[\mathrm{Ph}_{2} \mathrm{PO}_{2}\right]\left[\mathrm{NBu}_{4}\right]$ as tin scavenger. Subsequently, the triene $\mathbf{6 8}$ could be synthesized in excellent $82 \%$ 
yield. For biological studies the final fragment $\mathbf{6 8}$ was globally deprotected to the alcohol $\mathbf{6 9}$.

To this end, the O'Neil group successfully established a route to the dihydroarchazolid B fragment $\mathbf{6 8}$ in only 9 steps (longest linear synthesis). This route also proved that a retrosynthetic disconnection between $\mathrm{C} 12$ and $\mathrm{C} 13$ can be useful for new approaches to the 24-membered macrolide core. For the completion of the synthesis of $\mathbf{3}$ the side chain would have to be introduced, followed by an oxidation to the acid and a ring closing esterification.

\section{Concise synthesis of the thiazole fragment}

In an earlier synthesis the O'Neil group had already coupled a similar fragment $\mathbf{7 0}$ with the southern fragment $\mathbf{5 7}$ by an organometallic addition, however, with a lack of stereoselectivity in C23 position [45]. As shown in Scheme 14, they started with the deprotection of the primary TBS ether 70 and DMP oxidation to the aldehyde $\mathbf{7 1}$. The bromide $\mathbf{5 7}$, derived in two steps from literature-known ketone $\mathbf{7 2}$ [49], was converted to an organolithium compound which attacked the aldehyde to give the free alcohol $\mathbf{7 3}$ in 1:2.5 diasteroselectivity in favor of the undesired $R$-isomer of $\mathbf{7 3}$, which can be explained by the Felkin-Ahn model. For generation of only $(S)-\mathbf{7 3}$ the both epimers were oxidized to the ketone by DMP followed by reduction with L-selectride. Protection of the free alcohol with acetate and deprotection of the TES group was then required to install the carbamate with $\mathrm{CDI}$ and $\mathrm{MeNH}_{2}$. After deprotection, fragment 75 was synthesized in $67 \%$ yield over 2 steps.

Having these tactics in hand it will be interesting to follow the completion of the first synthesis of dihydroarchazolid B (3) by the O'Neil group and the biological data of this compound.

\section{Conclusion}

The discovery of the archazolids led to important advances in the understanding of the role of V-ATPases in cancer development and progression. Based on extensive studies with these macrolides as chemical tools V-ATPases have emerged as a completely novel and highly promising novel class of anticancer targets. Along these lines synthetic chemistry has played a pivotal role, not only by providing these scarce natural products for biological evaluation, but also in supplying novel analogues with tailored functional properties to decipher the target inhibitor interactions at a molecular level. Finally, the total syntheses of the Menche and Trauner group were also of key importance to assign the full stereochemistry in the first place. The various approaches discussed within this manuscript show the various tactics and strategies that may be employed in complex polyketide synthesis. Notable features of the total synthesis by the Menche group include the robustness of boron mediated aldol reactions to set both the characteristic assemblies of neighbored methyl and hydroxy group bearing stereogenic centers. In addition, an aldol condensation was shown to enable

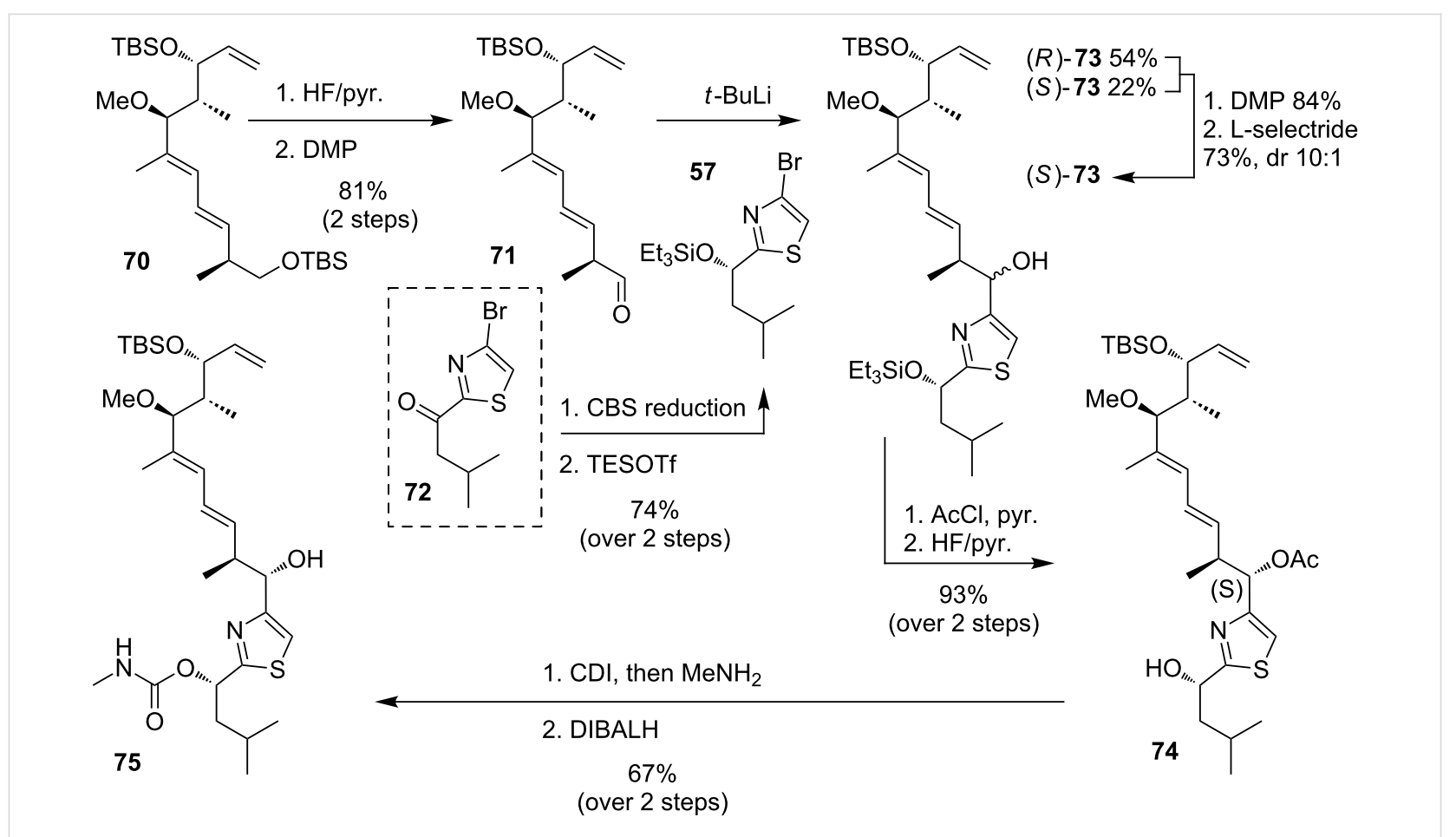


an efficient route for construction of a delicate triene system. The final $E$-selective Heck coupling on a highly elaborate substrate and the subsequent HWE macrocyclization are remarkable. The Trauner group in turn effectively employed various ruthenium-catalyzed reactions, including a relay ring-closing metathesis, which demonstrates the powerfulness of such a tactic even for highly elaborate substrates with several initiation positions. However, despite these advances and impressive total syntheses the design and development of a truly reliable and scalable route that will enable an access to gram amounts of thee scarce metabolites continues to present a key scientific challenge and the O'Neil group has already demonstrated that a more concise route may be possible. Efforts are now being directed in the design and development of truly practicable and scalable routes to more stable archazolids to enhance the further preclinical development of these novel anticancer agents. Particular importance will be the development of a truly reliable and high yielding macrocyclization method, while efficient methods for fragment syntheses have been established. It will also be interesting to follow whether synthetic chemists will be successful to establish a scalable route that will enable the synthesis of gram quantities of the authentic natural products or novel archazolids with likewise potent or even improved pharmacological and pharmacokinetic properties to fully exploit the extremely promising biological profile of these polyketide macrolides.

\section{Acknowledgements}

Financial support by the Deutsche Forschungsgemeinschaft (Forschergruppe 1406), the Volkswagenstiftung and the Fonds der Chemischen Industrie is gratefully acknowledged. We greatly appreciate the dedicated work of those members of our group who have developed this field of research and the stimulating cooperations with our scientific partners - their names can be seen from the literature cited.

\section{References}

1. Yeung, K.-S.; Paterson, I. Chem. Rev. 2005, 105, 4237-4313. doi:10.1021/cr040614c

2. Schetter, B.; Mahrwald, R. Angew. Chem., Int. Ed. 2006, 45, 7506-7525. doi:10.1002/anie.200602780

3. Dalby, S. M.; Paterson, I. Curr. Opin. Drug Discovery Dev. 2010, 13, 777-794.

4. Brodmann, T.; Lorenz, M.; Schäckel, R.; Simsek, S.; Kalesse, M. Synlett 2009, 174-192. doi:10.1055/s-0028-1087520

5. Li, J.; Menche, D. Synthesis 2009, 2293-2315. doi:10.1055/s-0029-1216881

6. Dieckmann, M.; Menche, D. Org. Lett. 2013, 15, 228-231. doi:10.1021/ol3033303

7. Dechert-Schmitt, A.-M. R.; Schmitt, D. C.; Gao, X.; Itoh, T.; Krische, M. J. Nat. Prod. Rep. 2014, 31, 504-513. doi:10.1039/c3np70076c
8. Seiple, I. B.; Zhang, Z.; Jakubec, P.; Langlois-Mercier, A.; Wright, P. M.; Hog, D. T.; Yabu, K.; Allu, S. R.; Fukuzaki, T.; Carlsen, P. N.; Kitamura, Y.; Zhou, X.; Condakes, M. L.; Szczypiński, F. T.; Green, W. D.; Myers, A. G. Nature 2016, 533, 338-345. doi:10.1038/nature17967

9. Bredenkamp, A.; Wegener, M.; Hummel, S.; Häring, A. P.; Kirsch, S. F. Chem. Commun. 2016, 52, 1875-1878. doi:10.1039/C5CC09328G

10. Mickel, S. J. Curr. Opin. Drug Discovery Dev. 2004, 7, 869-881.

11. Klar, U.; Buchmann, B.; Schwede, W.; Skuballa, W.; Hoffmann, J.; Lichtner, R. B. Angew. Chem., Int. Ed. 2006, 45, 7942-7948. doi:10.1002/anie.200602785

12. Cragg, G. M.; Grothaus, P. G.; Newman, D. J. Chem. Rev. 2009, 109, 3012-3043. doi:10.1021/cr900019j

13. Weissman, K. J.; Müller, R. Nat. Prod. Rep. 2010, 27, 1276-1295. doi:10.1039/c001260m

14. Nishi, T.; Forgac, M. Nat. Rev. Mol. Cell Biol. 2002, 3, 94-103. doi: $10.1038 / \mathrm{nrm} 729$

15. Jefferies, K. C.; Cipriano, D. J.; Forgac, M. Arch. Biochem. Biophys. 2008, 476, 33-42. doi:10.1016/j.abb.2008.03.025

16. Beyenbach, K. W.; Wieczorek, H. J. Exp. Biol. 2006, 209, 577-589. doi:10.1242/jeb.02014

17. Maxfield, F. R.; McGraw, T. E. Nat. Rev. Mol. Cell Biol. 2004, 5, 121-132. doi:10.1038/nrm1315

18. Hiesinger, P. R.; Fayyazuddin, A.; Mehta, S. Q.; Rosenmund, T.; Schulze, K. L.; Zhai, R. G.; Verstreken, P.; Cao, Y.; Zhou, Y.; Kunz, J.; Bellen, H. J. Cell 2005, 121, 607-620. doi:10.1016/j.cell.2005.03.012

19. Brown, D.; Paunescu, T. G.; Breton, S.; Marshansky, V. J. Exp. Biol. 2009, 212, 1762-1772. doi:10.1242/jeb.028803

20. Toyomura, T.; Murata, Y.; Yamamoto, A.; Oka, T.; Sun-Wada, G.-H.; Wada, Y.; Futai, M. J. Biol. Chem. 2003, 278, 22023-22030. doi:10.1074/jbc.M302436200

21. Pietrement, C.; Sun-Wada, G.-H.; Da Silva, N.; McKee, M.; Marshansky, V.; Brown, D.; Futai, M.; Breton, S. Biol. Reprod. 2006, 74, 185-194. doi:10.1095/biolreprod.105.043752

22. Hamm, R.; Chen, Y.-R.; Seo, E.-J.; Zeino, M.; Wu, C.-F.; Müller, R.; Yang, N.-S.; Efferth, T. Biochem. Pharmacol. 2014, 91, 18-30. doi:10.1016/j.bcp.2014.06.018

23. Scherer, O.; Steinmetz, H.; Kaether, C.; Weinigel, C.; Barz, D.; Kleinert, H.; Menche, D.; Müller, R.; Pergola, C.; Werz, O. Biochem. Pharmacol. 2014, 91, 490-500. doi:10.1016/j.bcp.2014.07.028

24. Sasse, F.; Steinmetz, H.; Höfle, G.; Reichenbach, H. J. Antibiot. 2003, 56, 520-525. doi:10.7164/antibiotics.56.520

25. Huss, M.; Sasse, F.; Kunze, B.; Jansen, R.; Steinmetz, H.; Ingenhorst, G.; Zeeck, A.; Wieczorek, H. BMC Biochem. 2005, 6, No. 13. doi:10.1186/1471-2091-6-13

26. Bockelmann, S.; Menche, D.; Rudolph, S.; Bender, T.; Grond, S.; von Zezschwitz, P.; Muench, S. P.; Wieczorek, H.; Huss, M. J. Biol. Chem. 2010, 285, 38304-38314. doi:10.1074/jbc.M110.137539

27. Gölz, J. P.; Bockelmann, S.; Mayer, K.; Steinhoff, H.-J.; Wieczorek, H.; Huss, M.; Klare, J. P.; Menche, D. ChemMedChem 2016, 11, 420-428. doi:10.1002/cmdc.201500500

28. Wiedmann, R. M.; von Schwarzenberg, K.; Palamidessi, A.; Schreiner, L.; Kubisch, R.; Liebl, J.; Schempp, C.; Trauner, D.; Vereb, G.; Zahler, S.; Wagner, E.; Müller, R.; Scita, G.; Vollmar, A. M. Cancer Res. 2012, 72, 5976-5987. doi:10.1158/0008-5472.CAN-12-1772

29. von Schwarzenberg, K.; Wiedmann, R. M.; Oak, P.; Schulz, S.; Zischka, H.; Wanner, G.; Efferth, T.; Trauner, D.; Vollmar, A. M. J. Biol. Chem. 2013, 288, 1385-1396. doi:10.1074/jbc.M112.412007 
30. Kubisch, R.; Fröhlich, T.; Arnold, G. J.; Schreiner, L.; von Schwarzenberg, K.; Roidl, A.; Vollmar, A. M.; Wagner, E. Int. J. Cancer 2014, 134, 2478-2488. doi:10.1002/ijc.28562

31. Schempp, C. M.; von Schwarzenberg, K.; Schreiner, L.; Kubisch, R.; Müller, R.; Wagner, E.; Vollmar, A. M. Mol. Cancer Ther. 2014, 13, 926-937. doi:10.1158/1535-7163.MCT-13-0484

32. von Schwarzenberg, K.; Lajtos, T.; Simon, L.; Müller, R.; Vereb, G.; Vollmar, A. M. Mol. Oncol. 2014, 8, 9-19. doi:10.1016/j.molonc.2013.08.011

33. Schneider, L. S.; von Schwarzenberg, K.; Lehr, T.; Ulrich, M.; Kubisch-Dohmen, R.; Liebl, J.; Trauner, D.; Menche, D.; Vollmar, A. M. Cancer Res. 2015, 75, 2863-2874. doi:10.1158/0008-5472.CAN-14-2097

34. Schneider, L. S.; Ulrich, M.; Lehr, T.; Menche, D.; Müller, R.; von Schwarzenberg, K. Mol. Oncol. 2016, 10, 1054-1062. doi:10.1016/j.molonc.2016.04.005

35. Pérez-Sayáns, M.; Somoza-Martin, J. M.; Barros-Angueira, F.; Rey, J. M. G.; García-García, A. Cancer Treat. Rev. 2009, 35, 707-713. doi:10.1016/j.ctrv.2009.08.003

36. Hernandez, A.; Serrano-Bueno, G.; Perez-Castineira, J. R.; Serrano, A. Curr. Pharm. Des. 2012, 18, 1383-1394. doi:10.2174/138161212799504821

37. Cotter, K.; Capecci, J.; Sennoune, S.; Huss, M.; Maier, M.; Martinez-Zaguilan, R.; Forgac, M. J. Biol. Chem. 2015, 290, 3680-3692. doi:10.1074/jbc.M114.611210

38. Menche, D.; Hassfeld, J.; Steinmetz, H.; Huss, M.; Wieczorek, H.; Sasse, F. J. Antibiot. 2007, 60, 328-331. doi:10.1038/ja.2007.43

39. Menche, D.; Hassfeld, J.; Steinmetz, H.; Huss, M.; Wieczorek, H.; Sasse, F. Eur. J. Org. Chem. 2007, 1196-1202. doi:10.1002/ejoc.200600912

40. Horstmann, N.; Essig, S.; Bockelmann, S.; Wieczorek, H.; Huss, M.; Sasse, F.; Menche, D. J. Nat. Prod. 2011, 74, 1100-1105. doi:10.1021/np200036v

41. Menche, D.; Hassfeld, J.; Li, J.; Rudolph, S. J. Am. Chem. Soc. 2007, 129, 6100-6101. doi:10.1021/ja071461o

42. Menche, D.; Hassfeld, J.; Li, J.; Mayer, K.; Rudolph, S. J. Org. Chem. 2009, 74, 7220-7229. doi:10.1021/jo901565n

43. Roethle, P. A.; Chen, I. T.; Trauner, D. J. Am. Chem. Soc. 2007, 129, 8960-8961. doi:10.1021/ja0733033

44. O'Neil, G. W.; Black, M. J. Synlett 2010, 107-110. doi:10.1055/s-0029-1218537

45. Tran, A. B.; Melly, G. C.; Doucette, R.; Ashcraft, B.; Sebren, L. J.; Havko, N.; Young, J. C.; O'Neil, G. W. Org. Biomol. Chem. 2011, 9 7671-7674. doi:10.1039/c1ob06446k

46. King, B. R.; Swick, S. M.; Schaefer, S. L.; Welch, J. R.; Hunter, E. F.; O'Neil, G. W. Synthesis 2014, 46, 2927-2936. doi:10.1055/s-0034-1379003

47. Swick, S. M.; Schaefer, S. L.; O'Neil, G. W. Tetrahedron Lett. 2015, 56, 4039-4042. doi:10.1016/j.tetlet.2015.05.014

48. O'Neil, G. W.; Craig, A. M.; Williams, J. R.; Young, J. C.; Spiegel, P. C. Synlett 2017, 28, 1101-1105. doi:10.1055/s-0036-1588413

49. Moulin, E.; Nevado, C.; Gagnepain, J.; Kelter, G.; Fiebig, H.-H.; Fürstner, A. Tetrahedron 2010, 66, 6421-6428. doi:10.1016/j.tet.2010.05.043

50. Xu, S.; Negishi, E.-i. Heterocycles 2014, 88, 845-877. doi:10.3987/REV-13-SR(S)5

51.Pop, L.; Lassalas, P.; Bencze, L. C.; Toşa, M. I.; Nagy, B.; Irimie, F. D.; Hoarau, C. Tetrahedron: Asymmetry 2012, 23, 474-481. doi:10.1016/j.tetasy.2012.03.014
52. de Paolis, M.; Chataigner, I.; Maddaluno, J. Top. Curr. Chem. 2012, 327, 87-146. doi:10.1007/128_2012_320

53. Negishi, E.-i.; Wang, G.; Rao, H.; Xu, Z. J. Org. Chem. 2010, 75, 3151-3182. doi:10.1021/jo1003218

54. Huang, Z.; Negishi, E.-i. J. Am. Chem. Soc. 2007, 129, 14788-14792. doi:10.1021/ja0772039

55. Menche, D.; Hassfeld, J.; Sasse, F.; Huss, M.; Wieczorek, H. Bioorg. Med. Chem. Lett. 2007, 17, 1732-1735. doi:10.1016/j.bmcl.2006.12.073

56. Persch, E.; Basile, T.; Bockelmann, S.; Huss, M.; Wieczorek, H.; Carlomagno, T.; Menche, D. Bioorg. Med. Chem. Lett. 2012, 22, 7735-7738. doi:10.1016/j.bmcl.2012.09.081

57. Dreisigacker, S.; Latek, D.; Bockelmann, S.; Huss, M.; Wieczorek, H.; Filipek, S.; Gohlke, H.; Menche, D.; Carlomagno, T. J. Chem. Inf. Model. 2012, 52, 2265-2272. doi:10.1021/ci300242d

58. Reker, D.; Perna, A. M.; Rodrigues, T.; Schneider, P.; Reutlinger, M.; Mönch, B.; Koeberle, A.; Lamers, C.; Gabler, M.; Steinmetz, H.; Müller, R.; Schubert-Zsilavecz, M.; Werz, O.; Schneider, G. Nat. Chem. 2014, 6, 1072-1078. doi:10.1038/nchem.2095

59. Hassfeld, J.; Farès, C.; Steinmetz, H.; Carlomagno, T.; Menche, D. Org. Lett. 2006, 8, 4751-4754. doi:10.1021/ol061831y

60. Farès, C.; Hassfeld, J.; Menche, D.; Carlomagno, T. Angew. Chem., Int. Ed. 2008, 47, 3722-3726. doi:10.1002/anie.200800225

61. Dieckmann, M.; Rudolph, S.; Dreisigacker, S.; Menche, D. J. Org. Chem. 2012, 77, 10782-10788. doi:10.1021/jo302134y

62. Kretschmer, M.; Dieckmann, M.; Li, P.; Rudolph, S.; Herkommer, D.; Troendlin, J.; Menche, D. Chem. - Eur. J. 2013, 19, 15993-16018. doi:10.1002/chem.201302197

63. Symkenberg, G.; Kalesse, M. Angew. Chem., Int. Ed. 2014, 53, 1795-1798. doi:10.1002/anie.201309386

64. Li, P.; Li, J.; Arikan, F.; Ahlbrecht, W.; Dieckmann, M.; Menche, D. J. Am. Chem. Soc. 2009, 131, 11678-11679. doi:10.1021/ja9056163

65. Li, P.; Li, J.; Arikan, F.; Ahlbrecht, W.; Dieckmann, M.; Menche, D. J. Org. Chem. 2010, 75, 2429-2444. doi:10.1021/jo100201f

66. Yang, Z.; Xu, X.; Yang, C.-H.; Tian, Y.; Chen, X.; Lian, L.; Pan, W.; Su, X.; Zhang, W.; Chen, Y. Org. Lett. 2016, 18, 5768-5770. doi:10.1021/acs.orglett.6b02729

67. Cowden, C. J.; Paterson, I. Org. React. 1997, 51, 1-200. doi:10.1002/0471264180.or051.01

68. Arikan, F.; Li, J.; Menche, D. Org. Lett. 2008, 10, 3521-3524. doi:10.1021/ol801292t

69. Kretschmer, M.; Menche, D. Synlett 2010, 2989-3007. doi:10.1055/s-0030-1259070

70. Essig, S.; Menche, D. Pure Appl. Chem. 2013, 85, 1103-1120. doi:10.1351/PAC-CON-12-09-12

71. Li, J.; Menche, D. Synthesis 2009, 1904-1908. doi:10.1055/s-0028-1088062

72. Still, W. C.; Gennari, C. Tetrahedron Lett. 1983, 24, 4405-4408. doi:10.1016/S0040-4039(00)85909-2

73. Baker, R.; Castro, J. L. J. Chem. Soc., Perkin Trans. 1 1990, 47-65. doi:10.1039/p19900000047

74. Inoue, T.; Liu, J.-F.; Buske, D. C.; Abiko, A. J. Org. Chem. 2002, 67, 5250-5256. doi:10.1021/jo0257896

75. Li, J.; Li, P.; Menche, D. Synlett 2009, 2417-2420. doi:10.1055/s-0029-1217819

76. Pitt, N.; Gani, D. Tetrahedron Lett. 1999, 40, 3811-3814. doi:10.1016/S0040-4039(99)00534-1

77. Brown, H. C.; Bhat, K. S.; Randad, R. S. J. Org. Chem. 1989, 54, 1570-1576. doi:10.1021/jo00268a017 
78. Corey, E. J.; Helal, C. J. Angew. Chem., Int. Ed. 1998, 37, 1986-2012. doi:10.1002/(SICI)1521-3773(19980817)37:15<1986::AID-ANIE1986>3 .0.CO;2-Z

79. Trost, B. M.; Gunzner, J. L. J. Am. Chem. Soc. 2001, 123, 9449-9450. doi:10.1021/ja011424b

80. Tanino, K.; Arakawa, K.; Satoh, M.; Iwata, Y.; Miyashita, M. Tetrahedron Lett. 2006, 47, 861-864. doi:10.1016/j.tetlet.2005.12.002

81. Trost, B. M.; Dean Toste, F. Tetrahedron Lett. 1999, 40, 7739-7743. doi:10.1016/S0040-4039(99)01639-1

82. Beaudry, C. M.; Trauner, D. Org. Lett. 2002, 4, 2221-2224. doi:10.1021/ol026069o

83. Evans, D. A.; Black, W. C. J. Am. Chem. Soc. 1993, 115, 4497-4513. doi:10.1021/ja00064a011

84. Kita, Y.; Maeda, H.; Omori, K.; Okuno, T.; Tamura, Y. Synlett 1993, 273-274. doi:10.1055/s-1993-22428

85. Farina, V.; Kapadia, S.; Krishnan, B.; Wang, C.; Liebeskind, L. S. J. Org. Chem. 1994, 59, 5905-5911. doi:10.1021/jo00099a018

86. Allred, G. D.; Liebeskind, L. S. J. Am. Chem. Soc. 1996, 118, 2748-2749. doi:10.1021/ja9541239

87. Molander, G. A.; Fumagalli, T. J. Org. Chem. 2006, 71, 5743-5747 doi:10.1021/jo0608366

88. van Horn, D. E.; Negishi, E.-i. J. Am. Chem. Soc. 1978, 100, 2252-2254. doi:10.1021/ja00475a058

89. Reetz, M. T. Acc. Chem. Res. 1993, 26, 462-468. doi:10.1021/ar00033a002

90. Chen, T.; Altmann, K.-H. Chemistry 2015, 21, 8403-8407. doi:10.1002/chem.201501252

91. Loiseleur, O.; Koch, G.; Cercus, J.; Schürch, F. Org. Process Res. Dev. 2005, 9, 259-271. doi:10.1021/op049807s

92. Dineen, T. A.; Roush, W. R. Org. Lett. 2004, 6, 2043-2046. doi:10.1021/ol049331x

93. Mandal, A. K.; Schneekloth, J. S., Jr.; Kuramochi, K.; Crews, C. M. Org. Lett. 2006, 8, 427-430. doi:10.1021/ol052620g

94. Paterson, I.; Yeung, K.-S.; Smaill, J. B. Synlett 1993, 774-776. doi:10.1055/s-1993-22605

95. Börding, S.; Bach, T. Chem. Commun. 2014, 50, 4901-4903. doi:10.1039/C4CC01338G

96. Fürstner, A.; Funel, J.-A.; Tremblay, M.; Bouchez, L. C.; Nevado, C.; Waser, M.; Ackerstaff, J.; Stimson, C. C. Chem. Commun. 2008, 2873-2875. doi:10.1039/B805299A

\section{License and Terms}

This is an Open Access article under the terms of the Creative Commons Attribution License (http://creativecommons.org/licenses/by/4.0), which permits unrestricted use, distribution, and reproduction in any medium, provided the original work is properly cited.

The license is subject to the Beilstein Journal of Organic Chemistry terms and conditions: (http://www.beilstein-journals.org/bjoc)

The definitive version of this article is the electronic one which can be found at:

doi:10.3762/bjoc. 13.108 